\title{
Relationship between perineal body length and the occurrence of perineal lacerations in low risk primigravidae: a prospective observational study
}

\author{
Pradeep Ganiga, Ritu A. Sharma*, Nikita Pitty
}

\author{
Department of Obstetrics and Gynaecology, AJ Institute of Medical Sciences and Research Centre, Mangalore, \\ Karnataka, India
}

Received: 28 December 2021

Accepted: 17 January 2022

\author{
*Correspondence: \\ Dr. Ritu A. Sharma, \\ E-mail: aritusharma95@gmail.com
}

Copyright: (C) the author(s), publisher and licensee Medip Academy. This is an open-access article distributed under the terms of the Creative Commons Attribution Non-Commercial License, which permits unrestricted non-commercial use, distribution, and reproduction in any medium, provided the original work is properly cited.

\begin{abstract}
Background: Birth canal lacerations include the injuries to cervix, vagina or perineum. Those of the perineum often follow vaginal delivery, and most are first-and second-degree lacerations. Third- and fourth- degree lacerations are considered Obstetrical anal sphincter injuries (OASIS), and their combined incidence varies from 0.5-5\%. Risk factors for these more complex perineal injuries have been studied. One important risk factor includes the length of the perineal body which plays an important role in determining the degree of perineal tears. The aim of the study was to assess the relationship between perineal body length and other characteristics, and occurrence of perineal lacerations during delivery in low risk primigravidae in an institution which advocates routine episiotomy for primigravidae.

Methods: This was a prospective observational study carried out in the department of obstetrics and gynaecology at AJ Institute of medical sciences among primigravidae who met the selection criteria and delivered between September 2021 and November 2021. A total of 80 women were recruited in this study. In this study, we measured the perineal body length at rest, while the patient was in a dorsal lithotomy position during 1st stage of labor, after delivery the new born's weight and head circumference were noted. The duration of second stage was noted. These parameters were studied in relation to the occurrence of perineal lacerations and the data was analysed.

Results: In the present study it was noted that 10 participants $(12.50 \%)$ had 3rd degree perineal tears and none had 4th degree perineal tears. With the perineal body length cut off of $3 \mathrm{~cm}$, the sensitivity to predict 3rd and 4th degree perineal tears were found to be $80 \%$, specificity of $90 \%$, positive predictive value of $53.33 \%$ and a negative predictive value of $96.92 \%$. The study concluded that a shorter perineal body length, was associated with the occurrence of a 3rd or 4th degree tear, $\mathrm{p}$ value of less than 0.00001 . The study also showed increased incidence of higher degree perineal tears with higher birth weight and head circumference of the newborn with p value of 0.015 and 0.02 respectively.

Conclusions: It can be concluded that Perineal body length of less than $3 \mathrm{~cm}$, higher birth weight and head circumference is associated with an increased incidence of higher order perineal tears. Perineal body length hence has a good ability to predict the occurrence of perineal tears.
\end{abstract}

Keywords: Primigravidae, Perineal body length, Birth weight, Head circumference, Perineal tears

\section{INTRODUCTION}

Normal birth is the least traumatic way to be born. Perineal lacerations can occur with normal deliveries but more commonly with IVD (Instrumental vaginal deliveries).
Posterior vaginal and perineal tears are common compared with anterior vaginal or vulval tears, this is due to good flexion of the head at delivery. ${ }^{1}$ The perineal body is the most common site of laceration; it is a mass of dense connective tissue that includes superficial and deep muscles of the perineal membrane, including the 
transverse perineal muscles and attachments of the bulbocavernosus muscles. Inferior to the perineal body is the anal sphincter complex which includes the internal and external sphincters, which circle the distal anus.

Although laceration rates vary based on patient characteristics, birth settings, and obstetric care provider practices, $53-79 \%$ of women will sustain some type of laceration at vaginal delivery, with most being first or second degree. ${ }^{15}$

\section{Classification of perineal lacerations}

Classification of perineal lacerations is as follows- (a) first degree: injury to the perineal skin only; (b) second degree: injury to perineum involving perineal muscles but not involving anal sphincter; (c) third degree: injury to perineum involving anal sphincter complex- $3 \mathrm{a}$ : less than $50 \%$ of external anal sphincter thickness torn, $3 \mathrm{~b}$ : More than $50 \%$ external anal sphincter thickness torn, 3c: both external anal sphincter and internal sphincter torn; and (d) fourth degree: injury to perineum involving anal sphincter complex (external anal sphincter and internal anal sphincter) and anal epithelium. Third and fourth degree tears are jointly referred to as Obstetric anal sphincter injuries (OASIS).

Second stage of labour: the period of time between full cervical dilatation and birth of the baby, during which the woman has an involuntary urge to bear down, as a result of expulsive uterine contractions. Women in the expulsive phase of second stage of labour should be encouraged and supported to follow their own urge to push. Techniques to reduce perineal trauma and facilitate spontaneous birth (including perineal massage, warm compress and a 'hands on' guarding of the perineum) are recommended. ${ }^{2}$

Although routine episiotomy is not recommended currently by the WHO 2018 and ACOG 2016(c), the rate of episiotomy varies and is mostly influenced by the center's and individual practitioner's judgement as to whether it is needed. ${ }^{12}$ Timely Episiotomy offers an advantage of preventing multiple perineal lacerations and also expidates delivery. A mediolateral episiotomy from the posterior fourchette going laterally to $60 \circ$ is preferable to avoid third- and fourth-degree tears. A sharp incision of 3-6 cm is given and depends on the length of the perineum. The superficial perineal muscles are incised and are comparable to the second-degree tear. It is done under local perineal infiltration of anaesthetic agent like lignocaine. Blood loss with episiotomy is minimized by giving it when head crowns. For the same reason it should be sutured as soon as possible. ${ }^{1}$

First-degree lacerations do not always require repair, and sutures are placed to control bleeding or restore anatomy.

Second-degree laceration correction as well as episiotomy repairs includes similar steps. Namely, these close the The vaginal epithelium and deeper tissues with a single, continuous, locking suture to reapproximate the vaginal mucosa to the level of hymen. ${ }^{3}$ After the vaginal component of the laceration is repaired, deeper perineal tissues are reapproximated by a single, continuous, nonlocking suture.

Small episiotomies may not require this deeper layer. With a similar continuous, nonlocking technique, which is faster than interrupted sutures and yields lesser pain the superficial transverse perineal and bulbospongiosus muscles are reapproximated restoring the perineal body. Last, the perineal skin is closed using a subcuticular or mattress stitch. ${ }^{6}$ Blunt needles are suitable. Commonly used suture materials are a rapidly absorbed polyglactin 910 (Vicryl rapide) or chromic catgut. Vicryl rapide being better with lower incidence of postsurgical pain and lower risk of wound dehiscence are cited as major advantages. ${ }^{4}$

For third-degree laceration repair, end-to-end technique is preferred. The cut ends of the external anal sphincter, are isolated and brought to the midline; a suture is placed through the EAS muscle, and four to six simple interrupted 2-0 or 3-0 sutures of polyglactin 910 are placed at the 3, 6, 9 , and 12 o'clock positions through the perisphincter connective tissue. The strength of this closure is derived from the connective tissue surrounding the sphinctercalled the capsule and not the striated muscle. Thus, serial interrupted sutures incorporate sphincter fibers and perisphincter connective tissue, to bring sphincter ends together. The sphincter muscle fibers are next reapposed by a figure-of-eight stitch. Last, the remainder of the fascia is closed with a stitch placed anterior to the sphincter cylinder and again with once placed superior to it. ${ }^{5}$ Delayed-absorbable material can provide sustained tensile strength during healing compared to routinely used suture material.

With the overlapping technique, the ends of the external anal sphincter are brought to the midline and lie atop one another. This method is only suitable for type $3 \mathrm{c}$ lacerations-those involving the external and internal anal sphincter. Two rows of mattress sutures travel through both sphincter ends to recreate the anal ring.

With fourth-degree laceration repairs, the torn edges of the rectal mucosa are re-approximated. At a point $1 \mathrm{~cm}$ proximal to the wound apex, sutures are placed approximately $0.5 \mathrm{~cm}$ apart in the rectal muscularis and do not enter the anorectal lumen. 4-0 polyglactin 910 or chromic gut can be used for this running suture line.

The next layer to cover the anorectal mucosa is formed by re-approximation of the Internal anal sphincter (IAS), which can be identified as the glistening white fibrous structure lying between the anal canal submucosa and the fibers of the external anal sphincter. This running, nonlocking closure is completed with 3-0 or 4-0 suture..$^{5,6}$

For reduction of infectious morbidity associated with anal sphincter lacerations, a single dose of antibiotic at the time 
of repair is recommended by the American College of Obstetricians and Gynecologists (2016c). A single dose of a second-generation cephalosporin is suitable, or clindamycin for penicillin-allergic women. With OASIS, postoperatively, stool softeners are prescribed for a week.

Unfortunately, normal function is not always ensured even with correct and complete surgical repair. Some women may experience continuing fecal incontinence caused by injury to the innervation of the pelvic floor musculature.

\section{Perineal laceration care}

Initially, locally applied ice packs help reduce swelling and allay discomfort. In subsequent days, warm sitz baths aid comfort and hygiene. Additionally, a small squirt bottle of warm water can cleanse the site after voiding or stooling.

Because pain may signal hematoma or perineal cellulitis, these sites should be examined carefully if pain is severe or persistent. In addition to pain, urinary retention may complicate episiotomy recovery.

Those with second-degree lacerations or anal sphincter tears, intercourse is usually proscribed until after the first puerperal visit at 6 weeks. Compared with women with intact perineum, those with perineal trauma show higher rates of delayed intercourse.

Different risk factors for perineal lacerations were studied earlier that included high infant weight, instrumental deliveries, malpositions and malpresentations, greater fetal head circumference, increased duration of second stage of labour, primiparity, post term delivery. However, there is some evidence that a shortened perineal body may also be a risk factor for severe lacerations.

The aim of the study was to assess the relationship between perineal body length and other characteristics, and occurrence of perineal lacerations extending into anal sphincter during delivery in low risk primigravidae in an institution which advocates routine episiotomy for primigravidae. $^{2}$

\section{METHODS}

This was a prospective observational study carried out in the department of obstetrics and gynaecology at AJ Institute of medical sciences among women who delivered between September2021 and November 2021.

A total of 80 women were recruited in this study.

\section{Inclusion criteria}

Inclusion criteria for given study were, primigravidae with singleton gestation cephalic presentation delivered between 37-42 weeks of gestation.

\section{Exclusion criteria}

Inclusion criteria for given study were, (a) birth weight $>4$ $\mathrm{kg}$; (b) head circumference $>95$ th percentile; (c) gestational diabetes mellitus; (d) growth restricted fetus; (e) instrumental delivery; (f) malpresentations and malpositions; (g) contracted pelvis and cephalopelvic disproportion; and (h) previous history of any perineal surgeries.

Length of the perineal body is defined as the length between the posterior of the fourchette and the midanus measured with a ruler and recorded to the nearest tenth of $\mathrm{cm}$.

In this study, we measured the perineal body length at rest, while the patient was in a dorsal lithotomy position during 1st stage of labor. The measurement was taken twice and was confirmed by a second person to minimize interobserver variability.

Right mediolateral episiotomy was done for all patients after infiltrating lignocaine $2 \%$ at the posterior fourchette, aspiration was performed to make sure no vessel has been penetrated, infiltration was performed beneath the vaginal mucosa and skin of perineum and deep into the perineal muscle.

Episiotomy was given when the perineum had thinned out and the baby's head was crowning. After birth the new born's weight and head circumference were noted.

The duration of second stage was noted.

\section{RESULTS}

The data of 80 participants were collected, and it was noted that the mean perineal body length of the participant was $3.16 \mathrm{~cm}$. The rate of $3 \mathrm{rd}$ degree perineal tear in the study group was found to be $12.5 \%$.

\section{Distribution of study participants based on degree of perineal lacerations}

55 participants of the study group had no perineal tears apart from the episiotomy.10 participants had first degree tears where only the perineal skin was involved. 5 women had second degree tears which involved the perineal muscles, 10 women had third degree tears which involved the anal sphincters.

None of the participants had fourth degree perineal injury involving the anal epithelium (Table 1).

\section{Comparison parameters}

Perineal body length

The average length of the perineal body of the study population was $3.16 \mathrm{~cm}$. 


\section{Duration of second stage}

The average duration of second stage of labour was 43.6 min.

\section{Birth weight}

The average birth weight of the newborn of the study participants was $3050 \mathrm{~g}$.

\section{Head circumference}

The average value of the head circumference of the newborn was $35 \mathrm{~cm}$ (Table 2).

\section{Percentage of study participants with various degrees of perineal tears}

No tears

There were no perineal tears additional to the episiotomy in $68.75 \%$ of the study participants.

First degree

$12.50 \%$ women sustained first degree perineal tears.

Second degree

$6.25 \%$ women sustained second degree perineal tears.

\section{Third degree}

$12.50 \%$ women sustained third degree perineal tears involving the anal sphincter.

None of the study participants had fourth degree perineal injuries (Figure 1).

\section{Distribution of the study participants based on length of the perineal body}

While 2 participants had perineal body length of less than $2.5 \mathrm{~cm}$, in 13 participants the perineal body measured 2.5 to $3 \mathrm{~cm}$. The rest of the candidates had a perineal body length between 3.1-3.5 cm (Figure 2).

\section{Length of perineal body in relation to perineal tears}

Among 10 women who sustained $3^{\text {rd }}$ and $4^{\text {th }}$ degree perineal tears one had perineal body length of $<2.5 \mathrm{~cm}, 7$ participants had length between 2.5 to $3 \mathrm{~cm}$, while 2 participants had length of $>3 \mathrm{~cm}$.

Among 70 women who had no perineal tears additional to episiotomy and those with first- or second-degree tears, only 1 had perineal body length of $<2.5 \mathrm{~cm}, 6$ had a length between $2.5-3 \mathrm{~cm}$ whereas 63 participants had a perineal body length of $>3 \mathrm{~cm}$. The study showed that a shorter perineal body length, was associated with the occurrence of a 3rd or 4th degree tear, $\mathrm{p}$ value of less than 0.00001 (Table 3 ). In our study, with the perineal body length cut off of $3 \mathrm{~cm}$, the sensitivity to predict $3 \mathrm{rd}$ and 4 th degree perineal tears was found to be $80 \%$, specificity of $90 \%$, positive predictive value of $53.33 \%$ and a negative predictive value of $96.92 \%$.

\section{Duration of second stage}

The duration of second stage of labor had no significant associating with the occurrence of a 3 rd or 4 th degree laceration, $p$ value 0.051 (Table 4).

\section{Birth weight}

The study showed a strong association between increased incidence of 3rd and 4th degree tears with increasing birth weight of the baby. When considering the categories II and III, the Odds of injury is more in group III, i.e.; the group with birth weight between 3.5 and $4 \mathrm{~kg}(\mathrm{OR}=5.3846$ at $95 \% \mathrm{CI}=1.1716-24.74$ at $\mathrm{p}=0.031$ ) (Table 5).

\section{Head circumference}

The study showed a statistically significant relationship between the occurrence of 3rd and 4th degree tears with increasing head circumference of the baby ( $p$ value of 0.023).

The Odds of a higher-grade perineal laceration are minimal at head circumference $\leq 50$ th centile $(\mathrm{OR}=7.2000$ at $95 \% \mathrm{CI}=1.4180$ to 36.5580 at $\mathrm{p}=0.02$ ) (Table 6 ).

Table 1: Distribution of study participants based on degree of perineal tears.

\begin{tabular}{|lllll|}
\hline \multirow{2}{*}{ None } & \multicolumn{4}{l}{ Degree of perineal tears } \\
& $\mathbf{1}^{\text {st }}$ & $\mathbf{2}^{\text {nd }}$ & $\mathbf{3}^{\text {rd }}$ & $\mathbf{4}^{\text {th }}$ \\
\hline $\mathbf{5 5}$ & 10 & 5 & 10 & 0 \\
\hline
\end{tabular}

Table 2: Comparison parameters.

\begin{tabular}{|l|l|}
\hline Parameters & Average \\
\hline Perineal body length & $3.16 \mathrm{~cm}$ \\
\hline Duration of $2^{\text {nd }}$ stage & $43.6 \mathrm{~min}$ \\
\hline Birth weight & $3050 \mathrm{~g}$ \\
\hline Head circumference at birth & $35 \mathrm{~cm}$ \\
\hline
\end{tabular}

Table 3: Perineal body length in relation to the degree of perineal tears.

\begin{tabular}{|c|c|c|c|}
\hline $\begin{array}{l}\text { Perineal } \\
\text { body } \\
\text { length } \\
(\mathrm{cm})\end{array}$ & $\begin{array}{l}\text { None, } 1^{\text {st }} \\
\text { or } 2^{\text {nd }} \\
\text { degree } \\
\text { tear }\end{array}$ & $\begin{array}{l}3^{\text {rd }} \text { or } 4^{\text {th }} \\
\text { degree } \\
\text { tear }\end{array}$ & Significance \\
\hline$<2.5$ & 1 & 1 & \multirow{3}{*}{$\begin{array}{l}\text { Chi } \\
\text { square }=28.167, \\
\text { p value }<0.00001\end{array}$} \\
\hline 2.5-3 & 6 & 7 & \\
\hline$>\mathbf{3}$ & 63 & 2 & \\
\hline
\end{tabular}


Table 4: Duration of second stage of labour in relation to degree of perineal tears.

\begin{tabular}{|llll|}
$\begin{array}{l}\text { Duration of } \\
\text { second } \\
\text { stage (hour) }\end{array}$ & $\begin{array}{l}\text { None, } 1^{\text {st }} \\
\text { or } 2^{\text {nd }} \\
\text { degree } \\
\text { tear }\end{array}$ & $\begin{array}{l}3^{\text {rd }} \text { or } \\
4^{\text {th }} \\
\text { degree } \\
\text { tear }\end{array}$ & Significance \\
\hline$\leq 1$ & 55 & 5 & $\begin{array}{l}\text { Chi } \\
\text { square }=3.8095, \\
\text { p value }=0.051\end{array}$ \\
\hline$>1$ & 15 & 5 &
\end{tabular}

Table 5: Birth weight in relation to degree of perineal tears.

\begin{tabular}{|llll|}
$\begin{array}{l}\text { Birth } \\
\text { weight }(\mathbf{g})\end{array}$ & $\begin{array}{l}\text { None, } \mathbf{1}^{\text {st }} \\
\text { or } 2^{\text {nd }} \\
\text { degree } \\
\text { tear }\end{array}$ & $\begin{array}{l}3^{\text {rd }} \text { or } \\
\mathbf{4}^{\text {th }} \\
\text { degree } \\
\text { tear }\end{array}$ & Significance \\
\hline $\mathbf{2 5 0 0 - 3 0 0 0}$ & 22 & 1 & Chi \\
\hline $\mathbf{3 0 0 0 - 3 5 0 0}$ & 35 & 3 & $\begin{array}{l}\text { square }=8.4577, \\
\text { p value }=0.051\end{array}$ \\
\hline $\mathbf{3 5 0 0 - 4 0 0 0}$ & 13 & 6 & \\
\hline
\end{tabular}

Table 6: Head circumference of the neonate in relation to degree of perineal tears.

\begin{tabular}{|llll|}
$\begin{array}{l}\text { Head } \\
\text { circumfere } \\
\text { nce in } \\
\text { centile }\end{array}$ & $\begin{array}{l}\text { None, } \mathbf{1}^{\text {st }} \\
\text { or } 2^{\text {nd }} \\
\text { degree } \\
\text { tear }\end{array}$ & $\begin{array}{l}\mathbf{3}^{\text {rd }} \text { or } \\
\mathbf{4}^{\text {th }} \\
\text { degree } \\
\text { tear }\end{array}$ & Significance \\
\hline 50th & 45 & 2 & Chi \\
75th-90th & 12 & 3 & $\begin{array}{l}\text { square }=7.5337, \\
\text { p value }=0.02\end{array}$ \\
\hline
\end{tabular}

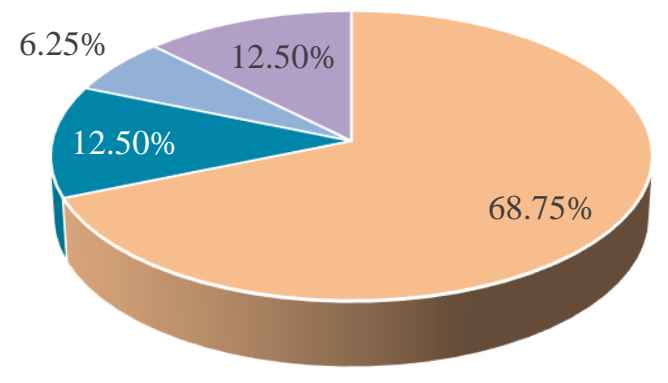

-1st Qtr - 2nd Qtr $\quad$ 3rd Qtr $\quad$ 4th Qtr

Figure 1: Distribution of study participants in percentage based on degree of perineal tears.

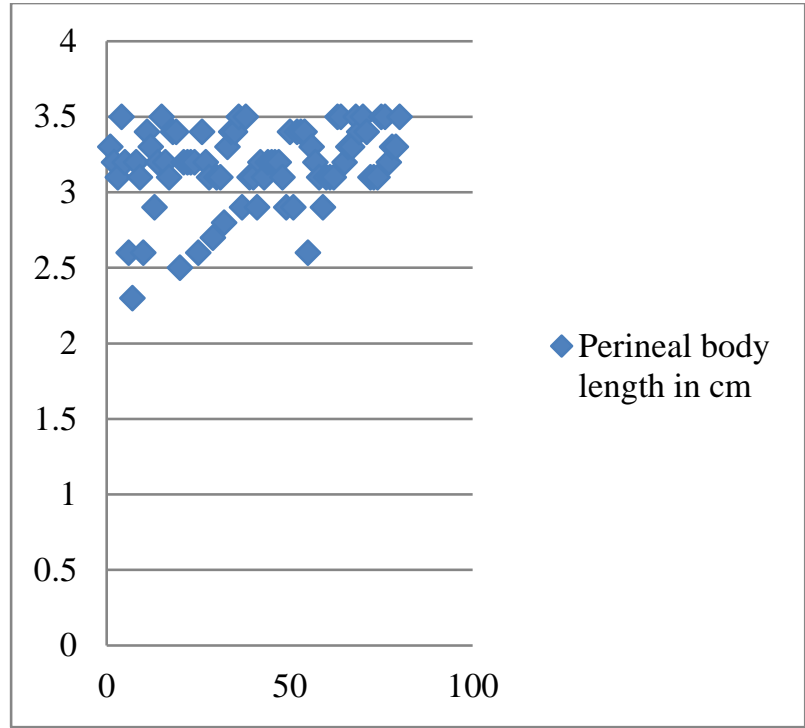

Figure 2: Distribution of study participants based on the length of the perineal body.

\section{DISCUSSION}

In the present study it was noted that 55 study participants $(68.75 \%)$ had no perineal tears, 10 participants $(12.50 \%)$ had 1 st degree perineal tears, 5 participants $(6.25 \%)$ had 2nd degree perineal tears and 10 participants $(12.50 \%)$ had 3rd degree perineal tears.

None of the study participants had 4th degree perineal tears. This majority of participants not having perineal injury and none having tears extending to the anal epithelium can be attributed to the routine episiotomy practiced in our institution for all primigravidae.

In a study conducted by Lane et al routine episiotomy was not practiced; out of 128 study participants who were primigravidae, 122 had none, 1st or 2nd degree perineal laceration whereas 5 had third- or fourth-degree perineal lacerations grouped together as OASIS. ${ }^{8}$

In another study conducted by Jansson et al risk factors for perineal injuries in primiparous women were studied. ${ }^{14}$ Out of 644 study participants, 55 were given episiotomy; 51 participants did not have OASIS $(94.4 \%), 3$ participants had third degree perineal tears $(5.6 \%)$ and none had 4 th degree perineal tears. This was similar to the findings in our study.

In the present study, the average length of the perineal body was found to be $3.16 \mathrm{~cm}$, the average birth weight was $3050 \mathrm{~g}$ and head circumference was $35 \mathrm{~cm}$. The average of second stage of labour duration was found to be $43.6 \mathrm{~min}$.

In the study conducted by Djusad et al, the mean length of perineal body was found to be $3.3 \pm 0.4 \mathrm{~cm}$, mean birth weight was $3054.3 \pm 324.9 \mathrm{~g}$, mean head circumference was 
$32.4 \pm 1.5 \mathrm{~cm}^{7}$ The mean duration of second stage of labour was found to be $48.6 \pm 13.3 \mathrm{~min}$.

In our study two participants had perineal body length of less than $2.5 \mathrm{~cm}, 13$ participants had perineal body length between 2.5 to $3 \mathrm{~cm}$. The rest of the candidates had a perineal body length between $3.1-3.5 \mathrm{~cm}$.

A total of 10 participants sustained third- and fourthdegree perineal tears out of which one had perineal body length of $<2.5 \mathrm{~cm}, 7$ participants had length between 2.5 to $3 \mathrm{~cm}$ and the remaining two participants had a perineal body length of $>3 \mathrm{~cm}$. The study showed that a shorter perineal body length, was associated with the occurrence of a 3rd or 4th degree tear, $\mathrm{p}$ value of less than 0.00001 .

The findings in our study are similar to the study conducted by Djusad et al, where bivariate analysis showed that there was a significant difference of mean perineal body length in high degree (third and fourth degrees) compared with low degree $(\mathrm{p}<0.001) .{ }^{7}$ The mean perineal body length among participants who suffered a third and fourth degree perineal tears was $2.9 \pm 0.2 \mathrm{~cm}$ while it was $3.3 \pm 0.4 \mathrm{~cm}$ in participants who had $1 \mathrm{st}$ and second degree tears.

In our study, with the perineal body length cut off of $3 \mathrm{~cm}$, the sensitivity to predict 3rd and 4th degree perineal tears were found to be $80 \%$, specificity of $90 \%$, positive predictive value of $53.33 \%$ and a negative predictive value of $96.92 \%$.

In a study conducted by Rizk et al the perineum length was considered at risk when the perineal body was less than 4 $\mathrm{cm}$ whereas in this study the cut off was $3 \mathrm{~cm} .{ }^{11}$

In another study conducted by Deering et al similar results were found but with a smaller cut off of $25 \mathrm{~mm} .{ }^{10}$

In the study conducted by Djusad et al it was found that with a perineal body length of $\leq 3 \mathrm{~cm}$ there was higher incidence of third- and fourth-degree perineal tears when mediolateral episiotomy was given, which is in accordance with our study. ${ }^{7}$

In the study conducted by Lane et al it was found that perineal body length of $\leq 3.5 \mathrm{~cm}$ was predictive of thirdand fourth-degree perineal lacerations $(\mathrm{p}=0.033){ }^{8}$

In the present study it was found that there was an increased incidence of 3rd and 4th degree perineal tears with higher birth weight of the baby. The Odds of 3rd degree perineal injury is more in the group with birth weight between 3.5 and $4 \mathrm{~kg} \quad(\mathrm{OR}=5.3846$ at $95 \% \mathrm{CI}$ $1.1716-24.74$ at $\mathrm{p}=0.031$ ).

In the study conducted by Djusad et al the risk of perineal tears of degree 3 and 4 was higher in the subjects whose infant's birth weight was $\geq 3150 \mathrm{~g}^{7}$
In another study conducted by Aytan et al it has been found that, in mediolateral episiotomy, a greater infant's birth weight with a mean of $>3755 \mathrm{~g}$ will cause a higher frequency of severe tearing $(\mathrm{p}<0.036){ }^{9}$

The infant's head circumference also has an important influence in causing the incidence of third- and fourthdegree perineal tears.

The present study showed a statistically significant relationship between the occurrence of 3rd and 4th degree tears with increasing head circumference of the baby ( $p$ value of 0.023 ). The Odds of a higher-grade perineal laceration are minimal at head circumference $\leq 50$ th centile $(\mathrm{OR}=7.2000$ at $95 \% \mathrm{CI}=1.4180$ to 36.5580 at $\mathrm{p}=0.02)$.

In a similar study conducted by Komorowski et al in episiotomy groups, the infant's head circumference of $\geq 33.5 \mathrm{~cm}$ was associated with an increased risk of third and fourth degree perineal tears $(\mathrm{p}<0.001) .{ }^{13}$

In our study there was no significant correlation between the duration of second stage of labour and the incidence of perineal tears $(\mathrm{p}=0.051)$.

This is similar to the study conducted by Djusad et al where there was no significant correlation found between the duration of second stage labour and perineal tears $(\mathrm{p}=0.33)^{7}$

In a study conducted by Lane et al second stage labour of $>99$ min was associated with an increased incidence of third- and fourth-degree perineal tears $(\mathrm{p}=0.03){ }^{8}$

\section{CONCLUSION}

From the results of this study we can conclude that measurement of the perineal body length, can give us a good idea about possibility of perineal lacerations. Predicting higher degree of perineal lacerations can help us to identify women who require liberal medio lateral episiotomy, a good perineal support and warm compress on the perineum as the baby's head stretches the perineum. The long-term morbidity associated with severe perineal lacerations remain significant. Characterizing risk factors and further research in the area of perineal anatomy may help avoid severe lacerations.

Funding: No funding sources

Conflict of interest: None declared

Ethical approval: The study was approved by the Institutional Ethics Committee

\section{REFERENCES}

1. Thakar R, Sultan AH. The Management and Prevention of Obstetric Perineal Trauma. The Management of Labour. Chennai: Orient Longmans; 2005: 252-268 
2. WHO. WHO recommendations: Intrapartum care for a positive childbirth experience, 2018. Available at: www.who.int/reproductivehealth. Accessed on 18 December 2021.

3. Kenton K, Mueller M. Episiotomy and obstetric anal sphincter lacerations. Cunningham and Gilstrap's Operative Obstetrics. In: Yeomans ER, Hoffman BL, Gilstrap LC III, eds. 3rd ed. New York, NY: McGrawHill; 2017.

4. Bharathi A, Reddy DB, Kote GS. A prospective randomized comparative study of vicryl rapide versus chromic catgut for episiotomy repair. J Clin Diagn Res. 2013;7(2):326-30.

5. Fernando RJ, Sultan AH, Kettle C, Thakar R. Methods of repair for obstetric anal sphincter injury. Cochrane Database Syst Rev. 2013;(12):2866.

6. Jallad K, Steele SE, Barber MD. Breakdown of Perineal Laceration Repair After Vaginal Delivery: A Case-Control Study. Female Pelvic Med Reconstr Surg. 2016;22(4):276-9.

7. Djusad S, Purwosunu Y, Hidayat F. Relationship between Perineal Body Length and Degree of Perineal Tears in Primigravidas Undergoing Vaginal Delivery with Episiotomy. Obstet Gynecol Int. 2021;2021:2621872.

8. Lane TL, Chung CP, Yandell PM, Kuehl TJ, Larsen WI. Perineal body length and perineal lacerations during delivery in primigravid patients. Proc (Bayl Univ Med Cent). 2017;30(2):151-3.

9. Aytan H, Tapisiz OL, Tuncay G, Avsar FA. Severe perineal lacerations in nulliparous women and episiotomy type. Eur J Obstet Gynecol Reprod Biol. 2005;121(1):46-50.
10. Deering SH, Carlson N, Stitely M, Allaire AD, Satin AJ. Perineal body length and lacerations at delivery. J Reprod Med. 2004;49(4):306-10.

11. Rizk DE, Thomas L. Relationship between the length of the perineum and position of the anus and vaginal delivery in primigravidae. Int Urogynecol J Pelvic Floor Dysfunct. 2000;11(2):79-83.

12. WHO. WHO recommendation on episiotomy policy, 2018. Available at: https://extranet.who.int/rhl/topics/preconceptionpreg nancychildbirthandpostpartumcare/careduringchildbi $\mathrm{rth} /$ careduringlabour-2ndstage/whorecommendationepisiotomy-policy-0. Accessed on 18 December 2021.

13. Komorowski LK, Leeman LM, Fullilove AM, Bedrick EJ, Migliaccio LD, Rogers RG. Does a large infant head or a short perineal body increase the risk of obstetrical perineal trauma? Birth. 2014;41(2):14752.

14. Jansson MH, Franzén K, Hiyoshi A, Tegerstedt G, Dahlgren H, Nilsson K. Risk factors for perineal and vaginal tears in primiparous women - the prospective POPRACT-cohort study. BMC Pregnancy Childbirth. 2020;20(1):749.

15. Committee on Practice Bulletins-Obstetrics. ACOG Practice Bulletin No. 198: Prevention and Management of Obstetric Lacerations at Vaginal Delivery. Obstet Gynecol. 2018;132(3):87-102.

Cite this article as: Ganiga $\mathrm{P}$, Sharma RA, Pitty N. Relationship between perineal body length and the occurrence of perineal lacerations in low risk primigravidae: a prospective observational study. Int J Reprod Contracept Obstet Gynecol 2022;11:420-6. 